\title{
HISTOGRAMS OBTAINED FROM COMPUTERIZED RADIOCARBON AGE CALIBRATION
}

\author{
MINZE STUIVER and PAULA REIMER
}

\section{Department of Geological Sciences and Quaternary Research Center \\ University of Washington, Seattle, Washington 98195}

\begin{abstract}
Two methods of assigning probability values to calendar years are compared by summing distributions for a large number of ${ }^{14} \mathrm{C}$ ages derived from samples initially distributed uniformly in calendar years. The radiocarbon ages are calibrated with both a hypothetical calibration curve and the internationally accepted one. The effect of the calibration curve on an ideal and a random sample population is examined.
\end{abstract}

In 1986 we published a computer program for radiocarbon age calibration (Stuiver and Reimer, 1986) which also was made available on a floppy disk to the radicarbon community. Since then, the program has undergone several improvements. Some of the features added to our disks (rev 2.0 and 2.1) mailed in 1987 are 1) the possibility of using moving averages of the calibration data when sample age errors are large, 2) the option of using a mixture of marine and terrestrial carbon, and 3) the calculation of the probability distribution of the calibrated age. A general description of the program capabilities can be found in our "User's Guide to the Programs CALIB and DISPLAY 2.1" (Stuiver \& Reimer, 1987). Here we restrict the discussion to technical aspects of the probability distribution calculation and its use.

As the ${ }^{14} \mathrm{C}$ age determination results from a physical measurement of the radioactivity of the sample, the probability distribution $\mathrm{P}(\mathrm{R})$ of the ${ }^{14} \mathrm{C}$ ages $\mathrm{R}$ around the measured ${ }^{14} \mathrm{C}$ age $\mathrm{U}$ is normal (Gaussian) with a standard deviation $\sigma_{\mathrm{s}}$. For the calibration of a ${ }^{14} \mathrm{C}$ age, the uncertainty $\sigma_{\mathrm{c}}$ in the calibration curve also has to be taken into account by substituting $\sigma=\sqrt{\sigma_{\mathrm{s}}^{2}+\sigma_{\mathrm{c}}^{2}}$ (Stuiver, 1982). Thus, the Gaussian $\mathrm{P}(\mathrm{R})$ distribution to be converted is

$$
P(R)=\frac{1}{\sigma \sqrt{2 \pi}} e^{\frac{-(R-U)^{2}}{2 \sigma^{2}}}
$$

To obtain $\mathrm{P}(\mathrm{T})$, the probability distribution along the calendar year axis, the $P(R)$ function is transformed to calendar year dependency using the calibration curve $R=g(T)$. Thus $P(T)$ has the form

$$
\mathrm{e}^{\frac{-(\mathrm{g}(\mathrm{T})-\mathrm{U})^{2}}{2 \sigma^{2}}}
$$


For a linear relationship between $\mathrm{R}$ and $\mathrm{T}$ (eg, $\mathrm{R}=\mathrm{bT}$ with $\mathrm{b}$ a constant), the new distribution is again of simple Gaussian form:

$$
\mathrm{e}^{\frac{-(\mathrm{T}-\mathrm{U} / \mathrm{b})^{2}}{2(\sigma / \mathrm{b})^{2}}}
$$

However, the wiggly character of the calibration curve usually yields a much more complicated function $\mathrm{g}(\mathrm{T})$ and a non-Gaussian $\mathrm{P}(\mathrm{T})$ distribution. Here one resorts to computerized transfer of the Gaussian $\mathrm{P}(\mathrm{R})$ distribution along the ${ }^{14} \mathrm{C}$ age axis to the calendar year axis. Graphically, this amounts to the transfer of small subdivisions (eg, for each ${ }^{14} \mathrm{C}$ year) of the $\mathrm{P}(\mathrm{R})$ distribution to the appropriate calendar year (Procedure 1). Alternatively, one can step through the calendar year axis (eg, using single calendar years), determine the corresponding ${ }^{14} \mathrm{C}$ age, and transfer to the T axis the corresponding probability portion of the $\mathrm{P}(\mathrm{R})$ distribution (Procedure 2). Procedure 1 has been applied by Robinson (1986) and Leese (1987), procedure 2 by Stuiver and Reimer (1987) and van der Plicht and Mook (1989).

There are some mathematical pitfalls that should be avoided with procedure 1 . The question arises how to allocate the $P(R)$ segment belonging to the ${ }^{14} \mathrm{C}$ age $\mathrm{R}$ when multiple intercepts are encountered. For instance, with three intercepts $T_{1}, T_{2}$ and $T_{3}$ does one allocate the full $P(R)$ segment to each calendar age, or one third $\mathrm{P}(\mathrm{R})$ to each? Or when encountering a flat portion of the calibration curve, say over a 20 calendar-year stretch, does one divide the $\mathrm{P}(\mathrm{R})$ segment by 20 to get the probability belonging to each calendar year? Procedure 2 , when stepping along the $\mathrm{T}$ axis, automatically allocates the full $P(R)$ value independent of the fact that certain $T$ values are part of multiple intercepts or part of horizontal portions of the curve. Opinions on the proper procedure vary. Subdividing the probabilities (method A) when multiple intercepts are encountered appears to be part of the first Robinson (1986) algorithm and the Leese (1988; pers commun, 1988) approach but not of ours (method B).

We tested both methods ( $\mathrm{A}$ and $\mathrm{B}$ ) by evaluating the disfigurement of a calendar-year block histogram as follows:

1) A block histogram is considered where, for each calendar year, the same probability of finding a sample is encountered. Total area of the $\mathrm{P}(\mathrm{T})$ block histogram is normalized to one for comparison purposes.

2) For each calendar year of the block histogram, the corresponding ${ }^{14} \mathrm{C}$ age is determined from the calibration curve. Each of these ${ }^{14} \mathrm{C}$ ages is then assigned a standard deviation (ie, all ages would be assigned a 12-yr error for the evaluation of high-precision counting).

3) For each ${ }^{14} \mathrm{C}$ age, the $\mathrm{P}(\mathrm{R})$ distribution belonging to that age is converted to a $\mathrm{P}(\mathrm{T})$ distribution. The area of each $\mathrm{P}(\mathrm{T})$ distribution is normalized to 1, all distributions are summed, and the summed probabilities are once again normalized on 1 .

Our premise is that the best procedure should yield the least distortion of the $\mathrm{P}(\mathrm{T})$ block histogram. 
Starting with a 300-yr-long block histogram, and assuming high-precision counting (12-yr error for the ${ }^{14} \mathrm{C}$ ages) as well as a linear calibration curve with one horizontal stretch of 20-yr (Fig 1), we generated the profiles given in Figures 1 and 2 for method A and B, respectively. Similarly, when

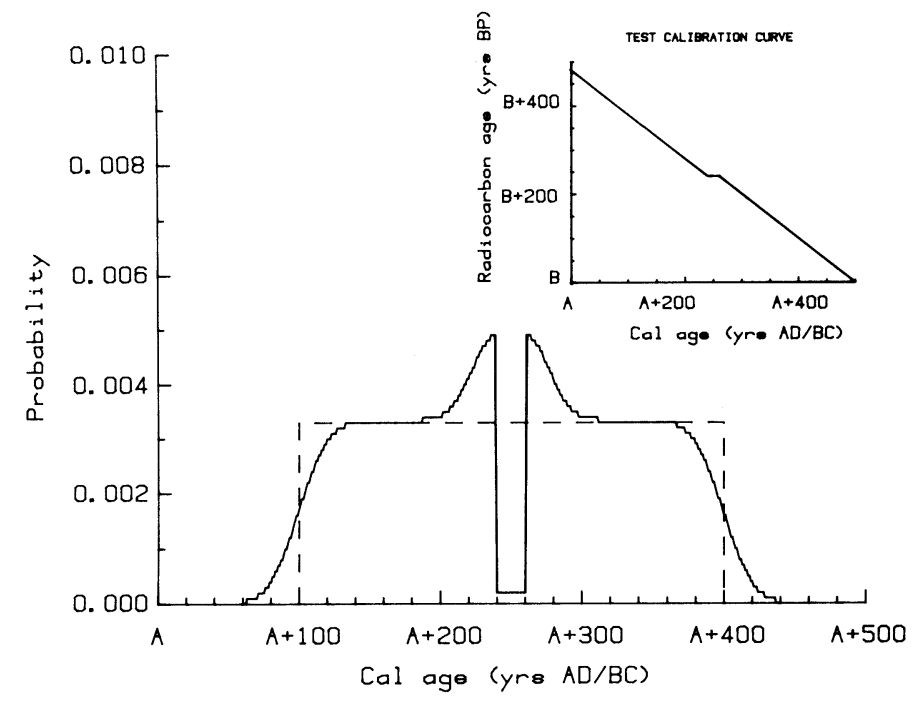

Fig 1 . Sum of the probability distributions (solid line) calculated for a 300 -yr block histogram (dotted line) using Method A with a 12-yr standard deviation (see text) and an artificially constructed calibration curve (inset)

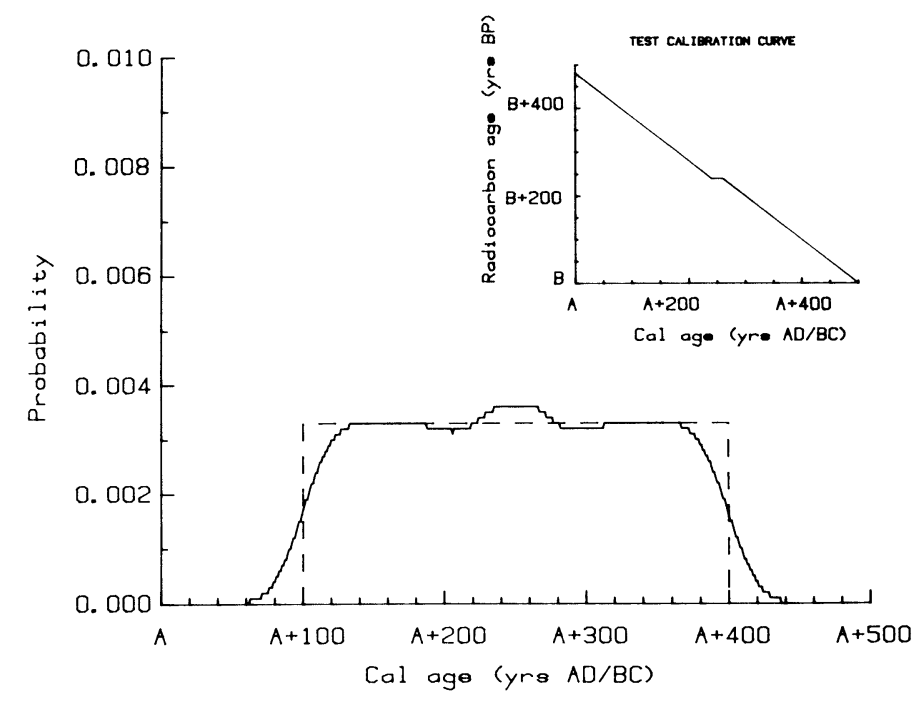

Fig 2. Same as above, using Method B 
using the actual calibration curve (Stuiver \& Pearson, 1986) for 300-yr stretch (AD 1000-1300), we obtained Figures 3 and 4, respectively, for method A and B.

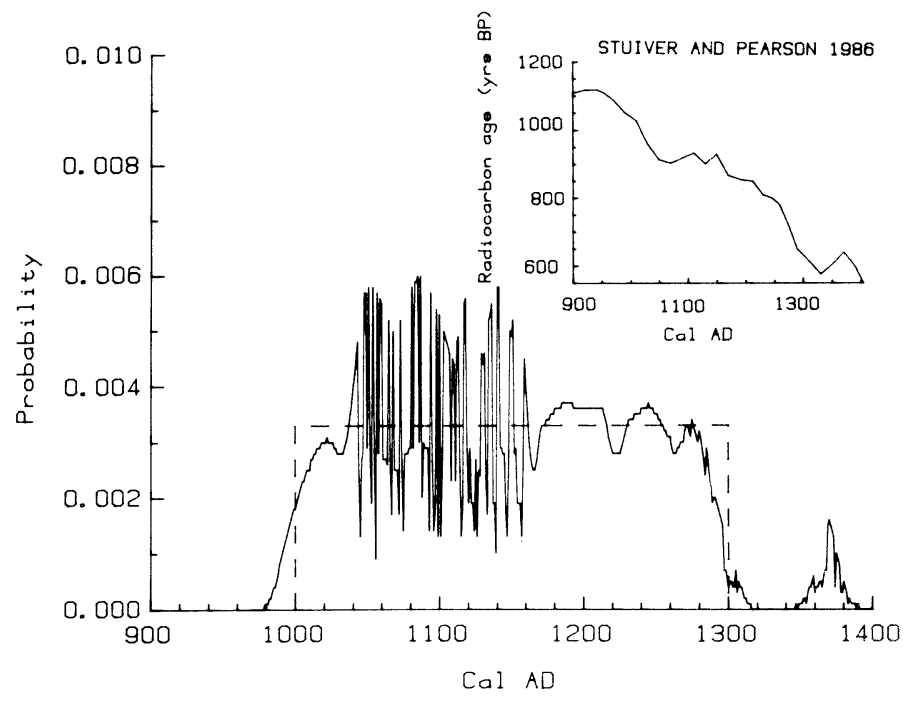

Fig 3. Same as above, from AD1000-1300 (dotted line) using Method A with a 12-yr standard deviation (see text) and the 20-yr atmospheric calibration curve (inset)

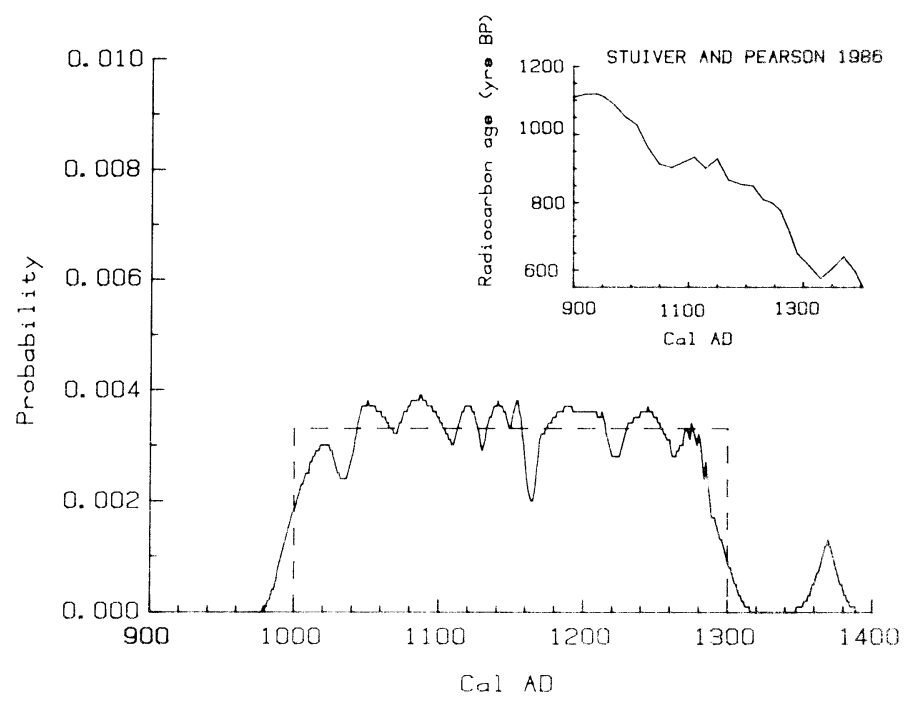

Fig 4. Same as above, using Method B 
Figures 1-4 show that $\mathrm{P}(\mathrm{T})$ histograms generated by method $\mathrm{B}$ resemble the initial distribution much closer than those generated by method A. At both ends of the histogram, there is probability "leakage" beyond the borders of the original distribution. This results partially from our allocating a standard deviation of $12 \mathrm{yr}$ to the ${ }^{14} \mathrm{C}$ ages, and partially from the properties of the calibration curve. The degree of leakage depends on the slope of the calibration curve and will be most extensive for horizontal portions of the curve.

Having generated these histograms, we investigated the degree of histogram distortion induced by the calibration curve (Method B only). This distortion is considerable for an individual age where a sample formed during a single calendar year $\mathrm{T}_{1}$, after ${ }^{14} \mathrm{C}$ dating is represented by a $\mathrm{P}(\mathrm{T})$ distribution that is often broader than a century. But what are the distortions to be expected when samples are collected for each calendar year in a cultural layer covering two centuries? Figures 5 and 6 give the results obtained for such a scenario with a standard error of either 12 or $50 \mathrm{yr}$ assigned to each ${ }^{14} \mathrm{C}$ age.

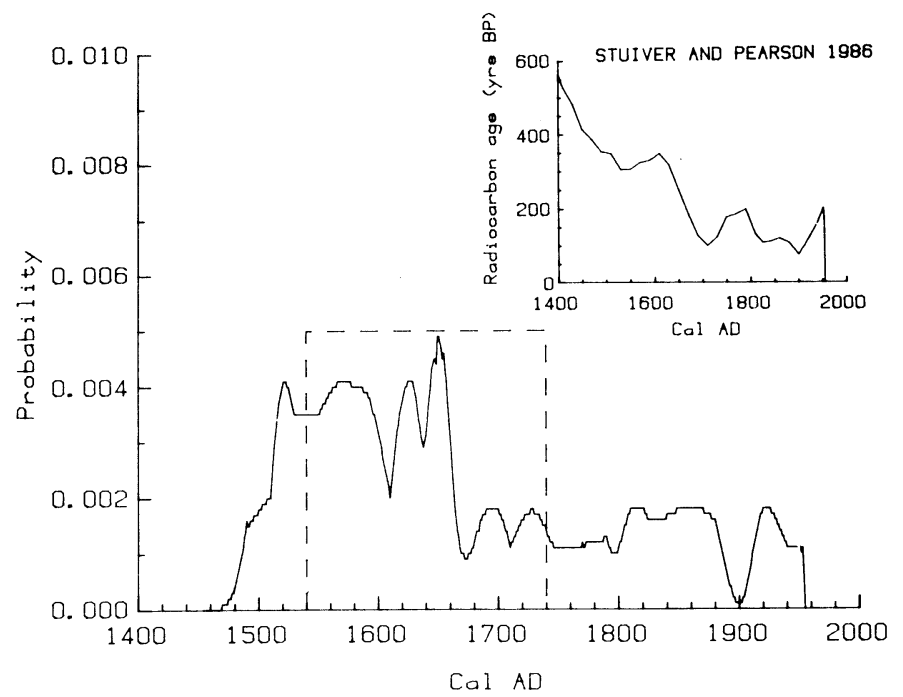

Fig 5. Same as above, calculated for : 200-yr block histogram from AD 1540-1740 (dotted line)

The part of the calculated $\mathrm{P}(\mathrm{T})$ probability distribution retained ("retained probability") in the original AD $1540-1740$ interval is $56 \%$ and $48 \%$, respectively, for assigned ${ }^{14} \mathrm{C}$ age errors of 12 and $50 \mathrm{yr}$. These are the percentages for optional conditions when a sample would have been collected (and grown) for each calendar year. A more realistic approach is to take a much smaller number, say 5 samples collected at random in a 200 -calendaryear cultural layer. Figure 7 gives the results for 5 randomly computerselected calendar years within the 200 -yr interval. Retained probability, for $\pm 50 \mathrm{yr}{ }^{14} \mathrm{C}$ age errors, ranges from $42-59 \%$, which is not substantially different from the $48 \%$ found for the much finer sample distribution in Figure 6. 


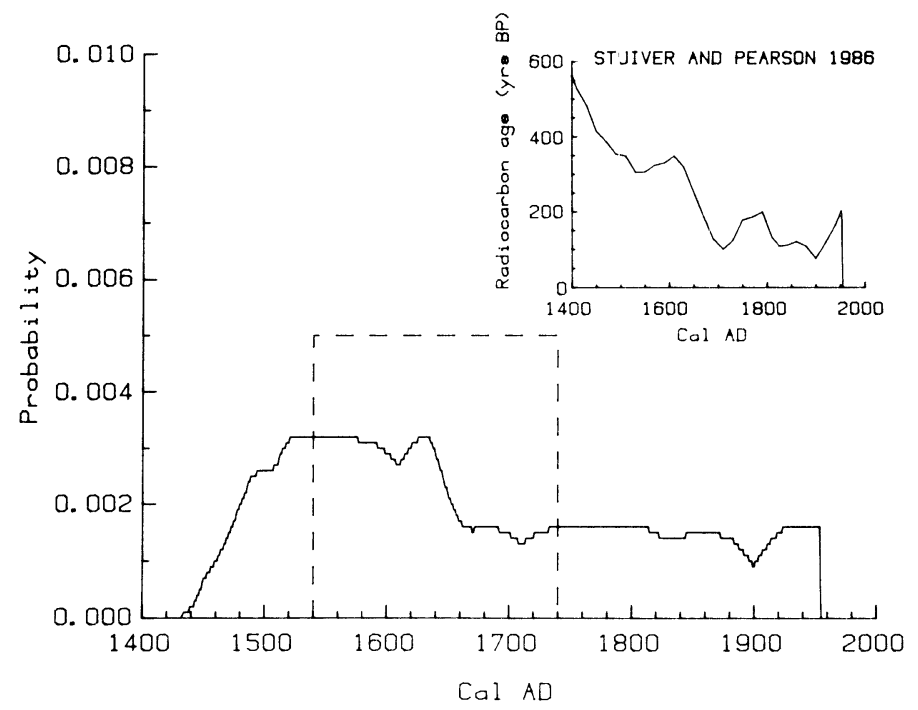

Fig 6. Same as above, with a $50-y r$ standard deviation (see text)
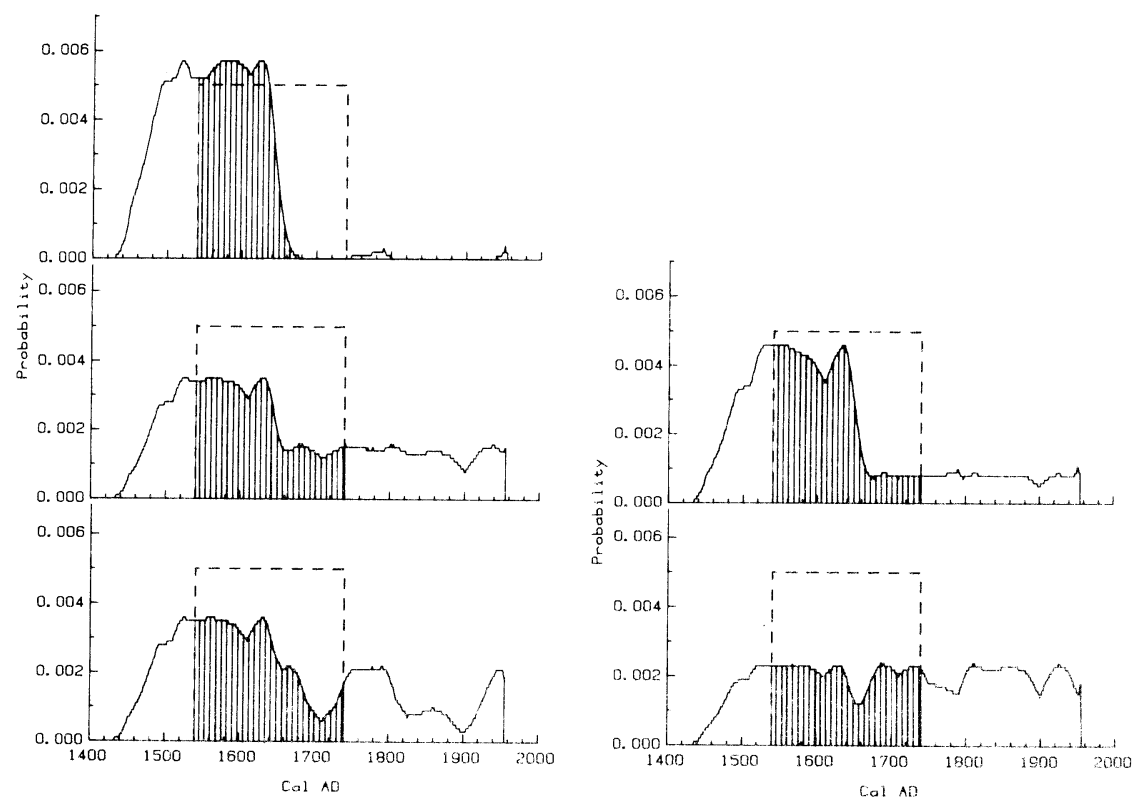

Fig 7. Summed probability distribution (solid lines) resulting from the conversion of $5{ }^{14} \mathrm{C}$ ages with standard deviations of $50 \mathrm{yr}$. The ${ }^{14} \mathrm{C}$ ages were derived from randomly selected calendar years ( 5 for each graph) in the AD $1540-1740$ interval (see text). Shaded areas denote the calculated $\mathrm{P}(\mathrm{T})$ probability for the original
histogram interval 
We conclude that distortion of histograms is unavoidable, even with the most precise mathematical procedure and high-precision ${ }^{14} \mathrm{C}$ dating. And as with dating individual samples, the degree of histogram distortion is most severe when horizontal portions of the calibration curve are encountered.

This research was supported through NSF grant BNS-8701720.

\section{REFERENCES}

Leese, MN, 1988, Methods for finding calendar date bands from multiple-valued radiocarbon calibration curves, in Ruggles, CLN and Rahtz, SPQ, eds, Computer and quantitative methods in archaeology 1987: BAR Internatl Ser 393, p 147-151.

Robinson, SW, 1986, A computational procedure for the utilization of high-precision radiocarbon curves: US Geol Survey open-file rept.

Stuiver, M, 1982, A high-precision calibration of the AD radicarbon time scale: Radiocarbon, $v$ 24 , no. 1 , p $1-26$.

Stuiver, M and Pearson, GW, 1986, High-precision calibration of the radiocarbon time scale, AD 1950-500 BC, in Stuiver, $\mathrm{M}$ and Kra, RS, eds, Internatl ${ }^{14} \mathrm{C}$ conf, 12 th, proc: Radiocarbon, v 28 , no. 2B, p 805-838.

Stuiver, $\mathrm{M}$ and Reimer, PJ, 1986, A computer program for radiocarbon age calibration, in Radiocarbon, v 28, no. 2B, p 1022-1030.

1987, User's guide to the programs CALIB and DISPLAY Rev. 2.1: Quaternary Isotope Lab, Univ Washington.

van der Plicht, J and Mook, WG, 1989, Calibration of radiocarbon ages by computer: Radiocarbon, this issue. 